\title{
Study on the Steam Source Selection of Feed Pump Turbine Based on Energy Matching
}

\author{
Jiongming Wang ${ }^{1}$, Feng Wang ${ }^{2}$, Zhenglong $\mathrm{Yu}^{1}$, Xiaochen $\mathrm{Chen}^{2}$, Xiaojie Lin ${ }^{1}$, Peng Zhang ${ }^{2}$, \\ Zhouyong Lin $^{1}$, Jincheng Chen ${ }^{2}$, Hongyu Guan ${ }^{1} \&$ Yutong Gong ${ }^{3}$ \\ ${ }^{1}$ Guo Neng (Quan Zhou) Thermal Power Co., Ltd, Quanzhou 362804, China \\ ${ }^{2}$ PowerChina Fujian Electric Power Engineering Co., Ltd, Fuzhou 350003, China \\ ${ }^{3}$ Key Laboratory of Energy Thermal Conversion and Control of Ministry of Education, School of Energy and \\ Environment, Southeast University, Nanjing 210096, China \\ Correspondence: Jiongming Wang, Assistant Engineer, Guodian Quanzhou Thermal Power Co. Ltd, Quanzhou \\ 362000 , China.
}

Received: May 12, 2021

doi:10.5539/eer.v11n1p86
Accepted: May 27, 2021

Online Published: May 31, 2021

\begin{abstract}
The first phase of a power plant has two subcritical $300 \mathrm{MW}$ units, and each boiler feed water pump is equipped with two with 50\% capacity steam driven feed pumps and one 50\% capacity electric start-up feed pump. The two steam pumps are put into operation during normal operation. After the heat supply transformation in the unit of the first phase of this power plant and based on the calculation and analysis of the heat balance of the unit, it is found that there will be insufficient output of the feed pump due to the insufficient steam source after the flow-through transformation, which will affect the water supply of the unit and reduce the energy utilization rate. To avoid this, the steam source of feed pump turbine needs to be selected again. Taking the original steam turbine condition of feed pump and the original steam source of feed pump turbine as the research basis, this paper makes analysis on the steam source transformation, and concludes the scheme of steam source selection and reconstruction based on energy matching. The feasibility of the scheme is tested and verified finally.
\end{abstract}

Keywords: combined heat and power generation (cogeneration), heating unit, feed pump turbine, steam source selection

\section{Introduction}

Nowadays, sustainable development strategy is the common development direction of all countries, and it is also the consensus of all mankind (Qin, 2014; Guo, Luo \& Ye, 2014). However, the biggest obstacle to sustainable development is the problem of energy. Countries all over the world are exploring to improve the energy utilization rate and pursue clean energy. The energy structure will determine the economic development of the region (Zhang, Gao, Wang \& Liu, 2014; Li, 2013; Wang \& Liu, 2015; Jin \& Zhang, 2014). Compared with separate generation, cogeneration can significantly improve the fuel efficiency and reduce the emission of pollutants. It has been recognized as one of the most important ways to conserve energy and improve the function of urban infrastructure in the world, and it also has good economic and social benefits (Liu, Zhao \& Pan, 2020; Rao, Qiu, Xu, Zhang, Cai \& Zhao, 2013; Yang, 2014).

Compared with the traditional thermal power generation, the utilization rate of coal can be increased by about $15 \%$ with cogeneration, while the central heating efficiency of thermal power plant boilers can be increased by more than 30\% compared with the decentralized heating efficiency of traditional small boilers (Zhang, E, Liu, Wang, Gan \& Liu, 2013; Pan, Liu \& Lei, 2020). Therefore, in developed countries, distributed energy such as combined heat and power generation has become an important measure to ensure power supply safety and energy conservation (Li, Yang, Ge \& Yang, 2012; Sun, 2020). Therefore, the National Development and Reform Commission issued the "Medium and Long Term Energy Conservation Plan" in November, 2004, which mentioned that the development of cogeneration is one of the ten key energy-saving projects during the "Eleventh Five-year Plan".

For the original equipment of the power plant, the coal consumption rate of power supply of the first phase unit after heating transformation can not meet the national requirement of average load below $310 \mathrm{~g} / \mathrm{kWh}$. In 
addition, the reliability of the unit is low because it is in the state of single unit operation for a long time or one unit in the second phase of the first phase. Finally, based on the heating capacity of the existing equipment and the current structure of heat users, it may not be able to meet the needs of new heat users in the future. Based on the above-mentioned needs, this power plant actively responds to the national policy of vigorously developing the cogeneration industry, aiming at improving the energy utilization efficiency as well as unit reliability and flexibility, to meet the needs of new heat users in the future. This also promotes the healthy and sustainable development of the company that this power plant is affiliated, and maintains the competitiveness of the company. Though the unit transformation of Phase 1 and Phase 2 has been made several times, this power plant still makes feasibility analysis to the first phase unit transformation in order to make heating transformation again.

However, based on the investigation and analysis of the heat balance calculation of the unit, it is found that after the through flow transformation according to the feasible scheme, the feed pump turbine will appear under the rated heating condition (high pressure heating $165 \mathrm{~T} / \mathrm{h}$, medium pressure heating $100 \mathrm{t} / \mathrm{h}$ ). According to the existing steam supply condition, the increase of steam extraction volume will lead to the decrease of steam source pressure and steam work capacity at the original four extraction position. The output of feed water pump is insufficient, which affects the water supply of the unit and causes the decrease of energy utilization. To avoid this situation, the steam source of feed water pump turbine will be re-selected. Through the analysis, it is found that the selection of steam source can be roughly divided into three schemes: the first scheme is the combined steam supply scheme of main steam and four extraction steam, which increases the original design of main steam to small unit high-pressure steam supply, when the output of small unit is insufficient, the four extraction steam and main steam are supplied at the same time to meet the steam supply demand of small unit; The second scheme is the cold re-supply steam scheme, which uses the cold re-supply auxiliary steam pipe to supply steam to the small turbine through the auxiliary steam header; The third scheme is the new steam source scheme for small turbine. Combined with this heating transformation, the steam extraction port for small turbine is added after 8 stages of intermediate pressure cylinder of steam turbine to improve the steam parameters of steam source and meet the output requirements of small turbine. Through comprehensive analysis, because the third scheme is more economical and reliable, and it solves the problem of insufficient steam source of small steam turbine from the root. Consequently, the third scheme is selected to transform the steam source of feed water pump turbine.

Therefore, this paper takes the original feed water pump turbine condition and the original feed water turbine steam source as the research basis of steam source transformation, through the steam source transformation analysis, this paper concludes the steam source selection transformation scheme based on the energy matching, and finally tests and verifies the feasibility of the transformation scheme.

\section{General Research Idea on Steam Source Selection of Feedwater Pump Turbine}

Figure 1 shows the reason, research basis and overall research idea of the power plant transformation. The research on steam source transformation of feed pump turbine is mainly based on the original steam source condition of feed pump turbine and the original steam source condition of feed pump turbine. Through the analysis of steam source transformation of the original condition, the transformation scheme is obtained. Finally, the transformation scheme is checked to further determine the feasibility of the transformation and make a more scientific and accurate judgment.

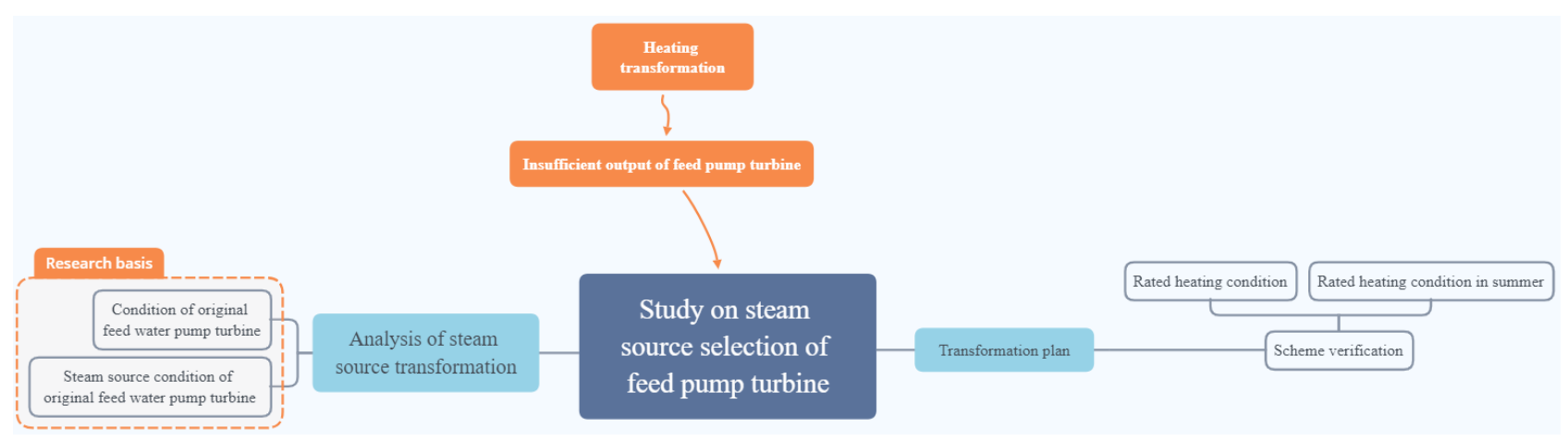

Figure 1. General Flow Chart on Reconstruction Research 


\section{Main Basis of Reconstruction}

\subsection{Condition of the Original Feed Water Pump Turbine}

The first phase of this power plant has two subcritical $300 \mathrm{MW}$ units. Each boiler feed water pump is equipped with two $50 \%$ capacity steam driven feed water pumps and one $50 \%$ capacity electric start-up feed water pump. During normal operation, two steam pumps are put into operation. The feed pump turbine consists of 7 stages, including single cylinder, double steam source, fresh steam internal switching, variable speed, variable power, impulse, condensing and lower exhaust. Among all the stages, the first stage is single row governing stage, and the 2-7 is pressure stage. The maximum continuous power is $6 \mathrm{MW}$. The rated inlet pressure and rated exhaust pressure are $0.8097 \mathrm{MPa}$ and $0.00528 \mathrm{MPa}$ respectively. The rated inlet temperature and exhaust temperature are $342.1{ }^{\circ} \mathrm{C}$ and $32.5{ }^{\circ} \mathrm{C}$ respectively, the steam consumption rate is $4.94 \mathrm{~kg} / \mathrm{kW} \cdot \mathrm{h}$, and the rated speed is 5160 $\mathrm{r} / \mathrm{min}$.

The pump turbine is designed with two steam sources, one is low pressure steam, and the other is high pressure steam. Low pressure steam is the main exhaust steam of the intermediate pressure cylinder of the steam turbine, that is the fourth stage extraction steam, whose working parameter is $0.8907 \mathrm{MPa} / 342.1^{\circ} \mathrm{C}$; The high pressure steam is the fresh steam of boiler, and its working parameter is $16.67 \mathrm{MPa} / 537^{\circ} \mathrm{C}$. Low pressure steam is used in normal operation of steam turbine. Under low load or high load, when the low pressure steam cannot meet the power demand of main feed water pump, high pressure steam will be used. In order to meet the operation needs, the steam turbine adopts the double inlet steam source distribution system. When the equipment is in normal operation, the intermediate pressure cylinder exhaust is used, that is four stage extraction is used. When the compliance is low or high, the main steam extraction is used. When the rated load of the main engine is less than $40 \%$, the high pressure steam is always on; When the rated load of the main engine reaches $15 \%$, the check valve in front of the low-pressure steam will be opened to let the low-pressure steam in. The low-pressure steam enters the low-pressure main steam valve through the extraction valve and its linkage isolation check valve, the steam chamber of the steam distribution mechanism enters the low-pressure nozzle chamber through the speed regulating valve, and then enters the steam turbine through the low-pressure nozzle to do work. The high-pressure steam enters the high-pressure main steam valve through the isolation valve, and the high-pressure speed regulating valve, and enters the high-pressure nozzle chamber through the flange nipple, and then through the high pressure nozzle group into the steam turbine to do work.

\subsection{Steam Source Condition of the Original Feed Water Pump Turbine}

Before the transformation, the small steam turbine used in the first phase unit of this power plant adopted single cylinder, single (double) steam source, high and low pressure steam source internal switching. The low-pressure steam source uses the four stage extraction steam of the steam turbine (equipped with low-pressure main steam valve and low-pressure nozzle), the allowable parameter variation range is $0.68 \sim 1.2 \mathrm{MPa}$, and the temperature is $310 \sim 400{ }^{\circ} \mathrm{C}$. High pressure steam source uses boiler main steam (equipped with high pressure main steam valve and high pressure nozzle). At the same time, the commissioning and start-up steam comes from the medium pressure auxiliary header, and the low-pressure steam source pipe is connected before the low-pressure steam source inlet of the high-pressure small steam turbine. High pressure steam source is not used (reheat cold section steam, equipped with medium pressure main steam valve and medium pressure nozzle, allowable parameter variation range is $3.2 \sim 4.5 \mathrm{MPa}$, temperature $280 \sim 350^{\circ} \mathrm{C}$ ).

During the construction period of the unit, the pipeline from the main steam to the small turbine is prone to overspeed shutdown due to valve leakage. Referring to the operation situation of similar units, this pipeline has not been used. In order to improve the reliability of the unit operation, the relevant steam supply pipeline and valve of the main steam to the small turbine are cancelled through consultation of all parties, and the low-pressure steam source is used for start-up and low load stage. The steam source is from the medium pressure auxiliary steam system, and the parameters of medium pressure auxiliary steam range from $0.59 \mathrm{MPa}$ to 0.99 $\mathrm{MPa}$ and from $341.7{ }^{\circ} \mathrm{C}$ to $341.7^{\circ} \mathrm{C}$. At present, the low-pressure steam sources of the unit are four stage extraction steam (steam source during normal operation of the unit) and medium pressure auxiliary steam (commissioning steam, which is supplied to the medium pressure auxiliary steam header by the cold re-extraction steam from the temporary unit through the high-pressure auxiliary steam header during the unit startup).

\section{Reconstruction Scheme Study on Steam Source}

In the heat supply transformation of the power plant, it is necessary to add $165 \mathrm{~T} / \mathrm{h}$ of extraction steam and 100 $\mathrm{t} / \mathrm{h}$ (maximum heating condition) for hot re extraction. The increase in extraction capacity leads to the decrease in the pressure of the source and the decrease in the steam power capacity. Figure 2 shows the operating 
conditions of the feed pump turbine which is calculated according to the original four extraction source steam supply condition, including the steam pressure of the steam source, the steam source steam temperature, the enthalpy value of the steam source, the exhaust pressure, the speed, the shaft power, the steam flow and the opening number of the small turbine regulating valve. It can be seen from the figure that after adding an extraction steam of $165 \mathrm{t} / \mathrm{h}$ and hot re-extraction of $100 \mathrm{t} / \mathrm{h}$, the regulating valve of the feed pump turbine needs to open three and a half valves, and the allowance of the half valve is small. The calculation is based on the condition that the turbine is new, the various clearances are suitable, the loss is small and the turbine efficiency is $80.8 \%$. If the turbine inlet and exhaust parameters are changed comprehensively, or the turbine is under $75 \%$ due to the long operation time, the turbine can not meet the output. However, the actual operation before the long-term transformation shows that the unit load is $229.82 \mathrm{MW}$, the main steam pressure is $16.255 \mathrm{MPa}$, the main steam is supplied with $102.38 \mathrm{t} / \mathrm{h}$, the first extraction is $14.103 \mathrm{t} / \mathrm{h}$, and the heat re heating is $24.735 \mathrm{t} / \mathrm{h}$, the small turbine has been fully opened at this time, which reflects that the phenomenon of insufficient output has begun to appear. Therefore, the steam source of the feed pump turbine needs to be adjusted again.
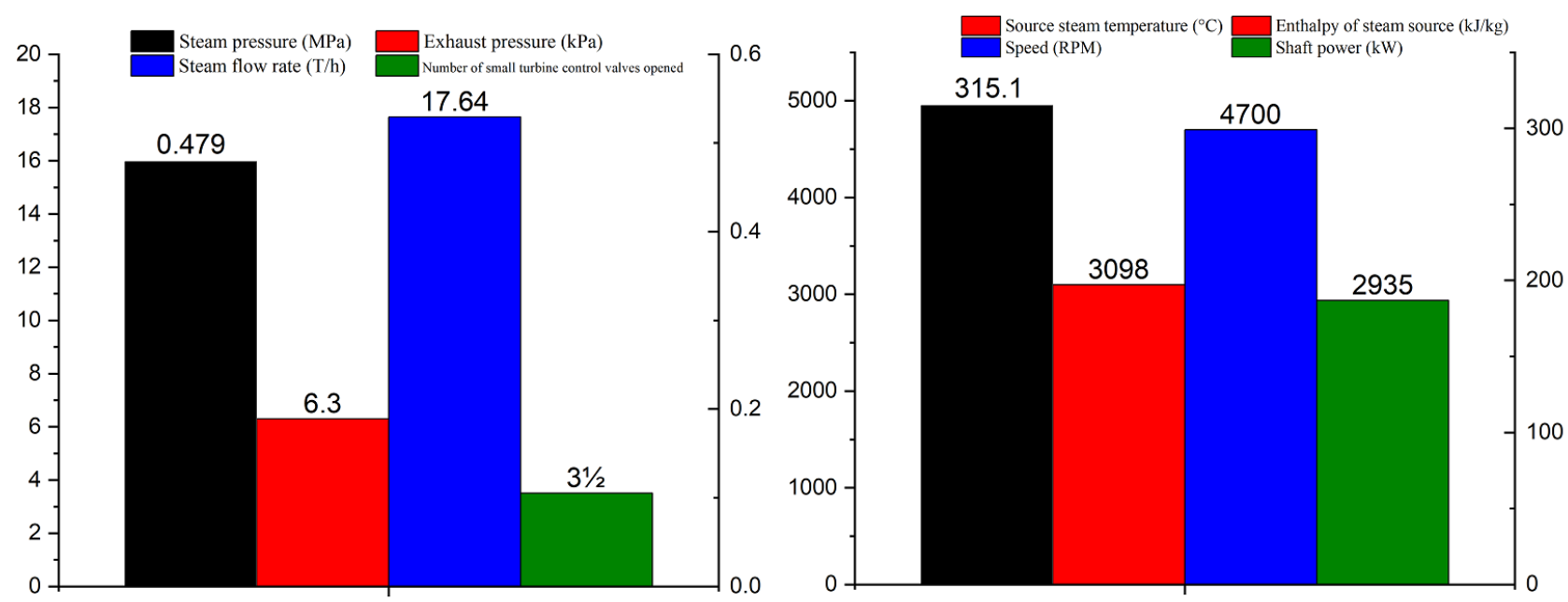

Figure 2. Four Extraction Steam Source Calculation to Feed Pump Turbine (single unit)

Figure 3 is the schematic diagram of steam source transformation of feed pump turbine. Combined with this heating transformation, the scheme increases the steam extraction port for small unit after 8 stages of intermediate pressure cylinder of turbine, adds 3.5 stages of steam extraction port, and increases the pipes, valves and corresponding pipe fittings from the steam extraction port to small unit, so as to improve the steam source steam parameters. Although the transformation scope is large, the retrofit economy is relatively high. And because of its close operation with the original steam source, it is easy to adjust and reliable in operation.

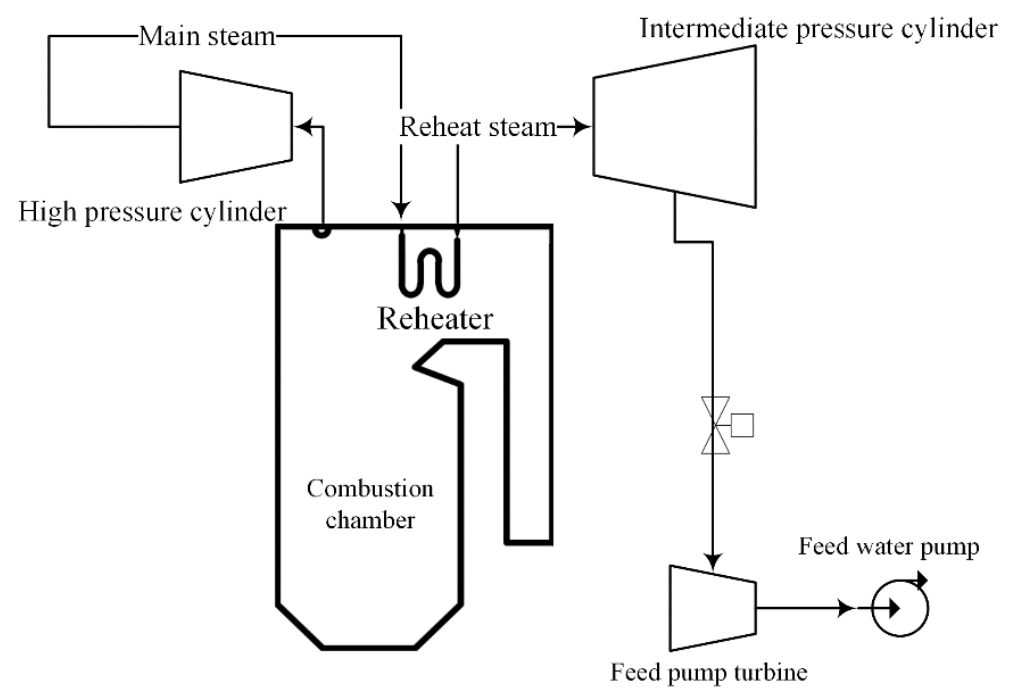

Figure 3. Reconstruction diagram of new stage 3.5 extraction port 


\section{Research on the Checking of Steam Source Reconstruction Scheme}

When the steam extraction (3.5 extraction) is used as the low-pressure gas source of the feed pump turbine as shown in scheme 3, according to the data of the heat balance diagram provided, the steam source parameters under the extreme conditions with higher requirements for the output of the feed pump turbine are the rated heating condition and the rated heating summer condition, and the pressure and temperature under the two conditions are shown in Figure 4.

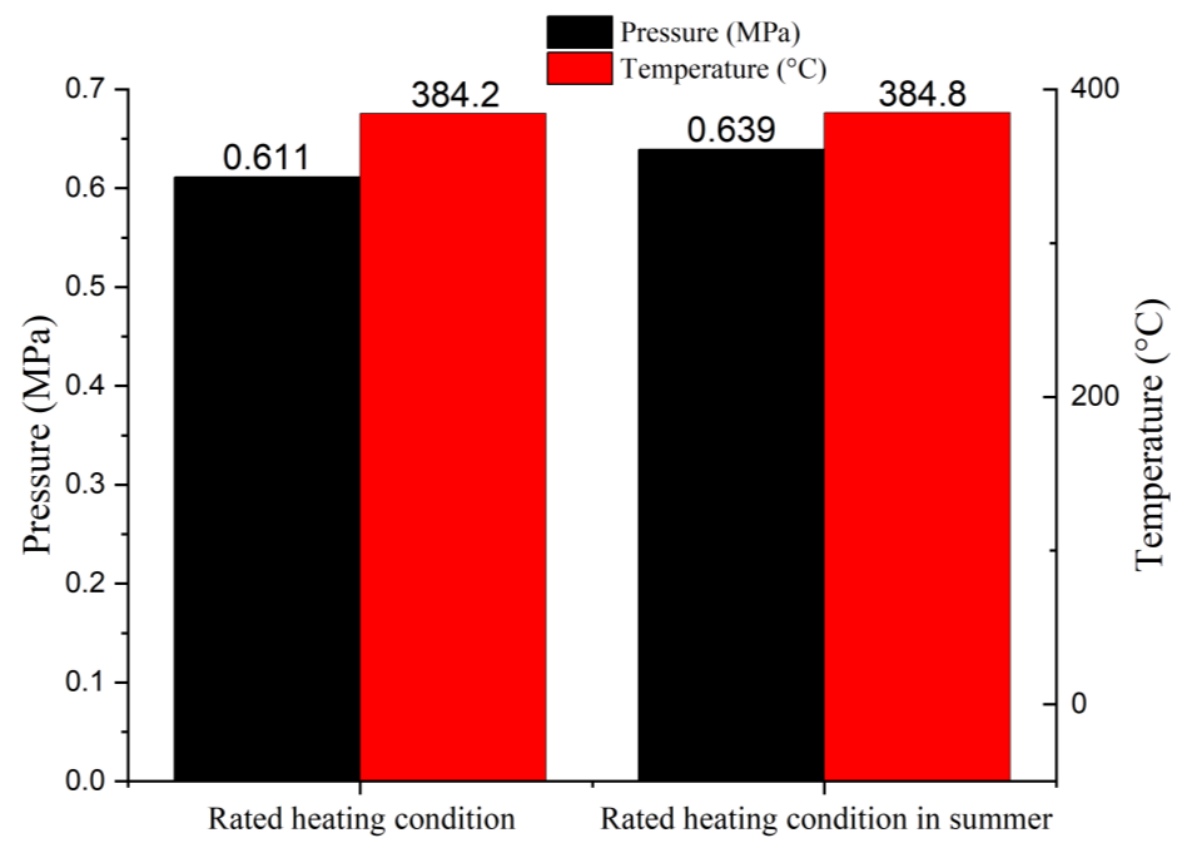

Figure 4. Parameters of extraction low pressure steam source

Figure 5 shows the thermodynamic parameters of the feed pump turbine when the low-pressure steam source is 3.5 extraction. It is considered that the pressure drop of the low-pressure steam source is $3 \%$ and the temperature drop is $1{ }^{\circ} \mathrm{C}$, including the steam pressure, steam temperature, steam flow, back pressure, speed and output power under the rated heating condition and the rated heating summer condition.

Under the rated heating condition, based on the parameters of the rated heating condition in the figure, the shaft power required to be output by the steam turbine is calculated as $5868.9 / 2=2935 \mathrm{~kW}$ according to the data of the heat balance diagram. The calculation result shows that $15.5 \mathrm{t} / \mathrm{h}$ steam is required, the opening of the control valve is about two and a half valves, and the full amount of one and a half control valve, which can fully meet the output demand of the small turbine. When the inlet pressure is $0.593 \mathrm{MPa}$ and the temperature is $383.2{ }^{\circ} \mathrm{C}$, the maximum steam intake of the feed pump is about $22 \mathrm{t} / \mathrm{h}$, and the surplus is large. When the inlet steam temperature and pressure drop by $10 \%$ and the turbine efficiency is more than $66 \%$, the output requirement of $2935 \mathrm{~kW}$ can be met.

Under the rated heating summer condition, based on the parameters of rated heating summer working condition in the figure, the shaft power required to be output by the steam turbine is calculated as $6089.5 / 2=3045 \mathrm{~kW}$ according to the heat balance data. The calculation result is $17.72 \mathrm{t} / \mathrm{h}$ steam is required, the regulating valve is opened by about two thirds of the valve, and the allowance of one regulating valve can meet the output demand of small turbine. The maximum steam intake of feed pump turbine is about $22.9 \mathrm{t} / \mathrm{h}$ when the steam inlet pressure is about $0.62 \mathrm{MPa}$ and the temperature is $383.8^{\circ} \mathrm{C}$, and the affluence is relatively large. When the temperature and pressure of steam inlet decrease by $10 \%$, the efficiency of steam turbine is over $73.5 \%$, the output requirement of $3045 \mathrm{~kW}$ can be met.

To sum up, the new 3.5 extraction as the steam source of feed pump turbine can meet the output demand of feed pump turbine with certain margin. The new addition of extraction steam is only supplied to the pump turbine, and the original four extraction steam is still used for deaerator and auxiliary steam. 

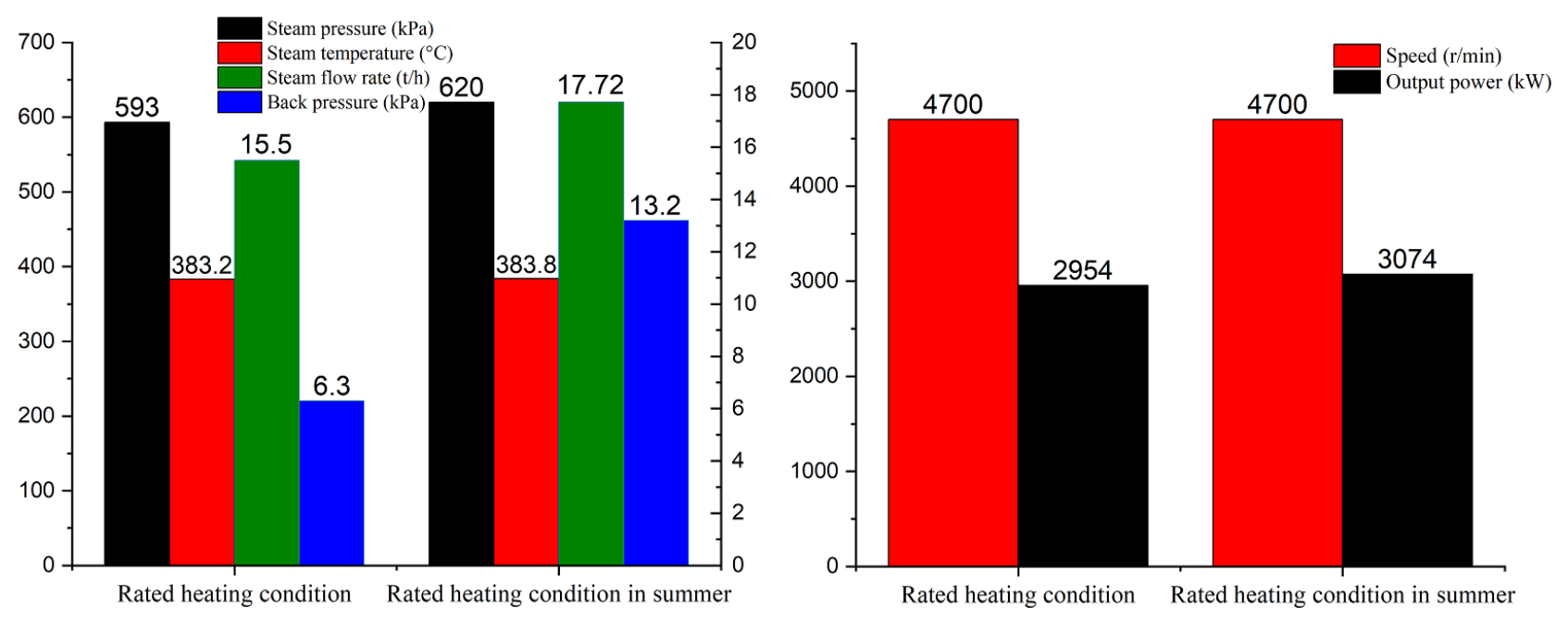

Figure 5. Thermodynamic parameters of feed pump turbine when low pressure steam source is 3.5

\section{Conclusion}

The problem of insufficient output of feed pump turbine occurred in the process of transformation of phase I unit in a power plant of a limited company. Based on the analysis of the original situation, the transformation scheme of different steam source selection is put forward. Through the comprehensive analysis of the transformation scope, economy and reliability, and finally combined with the heating transformation, the small unit steam extraction port is added after the intermediate pressure cylinder of the steam turbine is grade 8 , the 3.5 extraction port is added, and the pipes, valves and corresponding pipe fittings from the extraction port to the small unit are added, so as to improve the steam source steam parameters. Finally, the rationality and reliability of the transformation scheme are verified by checking the extreme conditions with higher output requirements.

\section{References}

Arkhypova, L. M., Mandryk, O. M., Moskalchuk, N. M., Prykhodko, M. M., \& Radlovska, K. O. (2021). Renewable energy resources in the system of sustainable development of Carpathian region of Ukraine. Journal of Physics: Conference Series, 1781(1).

Guo, C. Z., Luo, L. L., \& Ye, M. (2014). Empirical Analysis of Factors Influencing the Sustainable Development of Resource-based Cities. China Population Resources and Environment, 24(08), 81-89

He, J. H., Chen, J. H., Peng, H. M., \& Duan, H. L. (2021). Exploring the effect of renewable energy on low-carbon sustainable development in the Belt and Road Initiative countries: evidence from the spatial-temporal perspective. Environmental science and pollution research international, 2021. https://doi.org/10.1007/s11356-021-13611-4

Hou, J. S. (2021). Study on Flexible Transformation Mode of Cogeneration Unit. International Core Journal of Engineering, 7(5).

Jin, G. R., \& Zhang, L. (2014). Efficiency of Energy Saving and Emission Reduction in Small and Medium-sized Enterprises and Its Influencing Factors. China Industrial Economics, 01, 126-133.

Li, K. (2013). Energy-saving and Emission-abating Activity with Its Dynamic Characteristic in Different Provinces of China. China Soft Science Magazine, 2013(05), 144-157.

Li, P. F., Yang, Y. P., Ge, Z. H., \& Yang, Z. P. (2012). Analysis and Calculation on Energy Consumption of 300 MW CHP Heating Systems. Proceedings of the CSEE, 32(23), 15-20+144.

Liu, Z. Q., Zhao, Y., \& Pan, L. (2020). Analysis and Comparison of Energy Saving efficiency and emission reduction efficiency of thermal power between China and foreign countries. Thermal Power Generation, 2020, $1-10$

Pan, M. Y., Liu, N., \& Lei, J. Y. (2020). Dynamic Partition Method for Distributed Energy Cluster with Combined Heat and Power Unit. Automation of Electric Power Systems, 45(1), 1-10.

Polenske Karen R., \& Lin, X. N. (1993). Conserving energy to reduce carbon dioxide emissions in China. North-Holland, 4(2). https://doi.org/10.1016/0954-349X(93)90018-F 
Qin, D. H. (2014). Climate change science and sustainable development. Progress in Geography, 33(07), 874-883.

Rao, Q. H., Qiu, Y., Xu, L. Z., Zhang, J. S., Cai, R. Y., \& Zhao, Y. (2013). Evaluation of energy saving and emission reduction performance based on multi-object decision model. Acta Scientiae Circumstantiae, 33(02): 617-625

Shankar, R., \& Rivera, W. (2021). Analysis of an integrated thermal separation and flashing cooling cogeneration cycle. Applied Thermal Engineering, 190. https://doi.org/10.1016/j.applthermaleng.2021.116773

Sobczyk Wiktoria \& Sobczyk Eugeniusz Jacek (2021). Varying the Energy Mix in the EU-28 and in Poland as a Step towards Sustainable Development. Energies, 14(5). https://doi.org/10.3390/en14051502

Sun, T. H. (2020). Consideration and research on energy efficiency index evaluation of back pressure cogeneration unit. Energy Conservation, 39(09), 49-53

Wang, B., \& Liu, G. T. (2015). Energy Conservation and Emission Reduction and China's Green Economic Growth-Based on a Total Factor Productivity Perspective. China Industrial Economics, 05, 57-69.

Yang, J. (2014). Research on Multi-objective Optimization Decision-making of Energy Conservation and Emission Reduction for Coal Mines. Doctoral Dissertation. China University of Geosciences.

Yu, W., Wang, H. T., \& Ge, Z. (2021) Comprehensive analysis of a novel power and cooling cogeneration system based on organic Rankine cycle and ejector refrigeration cycle. Energy Conversion and Management, 232. https://doi.org/10.1016/j.enconman.2021.113898

Zhang, G. X., Gao, X. L., Wang, Y. L., \& Liu, M. X. (2014). Policy synergy: A new perspective of the research on energy conservation and emission reduction policies in China. System Engineering-Theory \& Practice, $34(03), 545-559$

Zhang, Y., E, Z. J., Liu, W. P., Wang, W. C., Gan, Z. Y., \& Liu, W. (2013). Study and Application of Heating Units' Peak-load Regulating Capacity. Proceedings of the CSU-EPSA, 25(03), 115-118.

Zhen, W., Qin, Q. D., \& Wei, Y. M. (2017). Spatio-temporal patterns of energy consumption-related GHG emissions in China's crop production systems. Energy Policy, 104. https://doi.org/10.1016/j.enpol.2017.01.051

Żołądek Maciej, Figaj Rafał \& Sornek Krzysztof (2021). Energy analysis of a micro-scale biomass cogeneration system. Energy Conversion and Management, 236. https://doi.org/10.1016/j.enconman.2021.114079

\section{Copyrights}

Copyright for this article is retained by the author(s), with first publication rights granted to the journal.

This is an open-access article distributed under the terms and conditions of the Creative Commons Attribution license (http://creativecommons.org/licenses/by/4.0/). 